\title{
Effect of pool confinement on pressures around a block impacted by plunging aerated jets
}

\author{
Rafael Duarte, Anton J. Schleiss, and António Pinheiro
}

\begin{abstract}
The erosion caused by jets issued from hydraulic structures progressively develops a confined scour-hole on the riverbed. A realistic scour assessment must consider both the influence of the air entrained when the jet plunges into the pool and the flow patterns induced by bottom geometry. This experimental study systematically analyzes the combined influence of jet aeration and pool confinement on the dynamic pressures affecting the water-rock interface and inside 3D fissures around a block. The results show that confinement reduces mean pressures and pressure fluctuations when the pool is relatively deep, but almost no influence is found when the pool is shallow, while air entrainment has an opposite effect. Three mechanisms are identified, two of them depend on the pool depth. Furthermore, when a block is mobile, pressures are attenuated inside the surrounding joints. The consequent block vibrations and the presence of air reduce pressure waves celerity inside the fissures.
\end{abstract}

Key words: air entrainment, plunging jets, flow pattern, rock scour, plunge pool, high-velocity jets, lateral jet confinement.

Résumé : L'érosion causée par des jets issus de structures hydrauliques développe progressivement une fosse confinée sur le lit. Une évaluation réaliste de l'affouillement considère l'influence de l'air entrainé quand le jet plonge, ainsi que des flux induits par la géométrie du fond. Cette étude expérimentale analyse systématiquement l'influence combinée de l'aération et du confinement de la fosse sur les pressions dynamiques affectant l'interface eau-roche et les fissures 3D autour d'un bloc. Les résultats montrent que le confinement réduit les pressions moyennes et ses fluctuations si le bassin est relativement profond, mais l'influence est négligeable quand le bassin est peu profond, tandis que l'aération a un effet inverse. Trois mécanismes sont identifiés, deux d'entre eux dépendent de la profondeur du bassin. Quand un bloc est mobile, les pressions sont atténuées à l'intérieur des fissures. Les vibrations du bloc, comme la présence d'air, réduisent la célérité des ondes de pression dans les fissures.

Mots-clés : entraînement d'air, jets plongeants, caractéristiques d'écoulement, affouillement, fosse d'érosion, jets à haute vitesse, confinement latérale du jet.

\section{Introduction}

High-velocity jets issued from high-head hydraulic structures, such as dams, have the potential to generate erosion when impacting rocky riverbeds, where a confined scour hole progressively develops (Schleiss 2002). To avoid any risk the scour hole may represent to the stability of the dam itself, it is of crucial concern that hydraulic engineers estimate scour evolution precisely.

Typically, the jet will have a trajectory in the air after it has been issued from the flood release structure, during which it will progressively incorporate air through its perimeter due to internal turbulence. When plunging in the receiving pool, a very large quantity of air is entrained between the perimeter of the jet and the pool surface. The aerated jet will then dissipate a part of its energy along the pool depth and the remaining energy will be converted to dynamic pressures acting on the bottom of the pool.

The progressive modification of the bottom geometry caused by scouring has a significant effect on how the jet dissipates and therefore on the dynamic pressures acting on the water-rock interface and inside the underlying fissures of the rock mass (Manso 2006). Equilibrium or ultimate scour is reached when the incoming energy of the jet is dissipated to an extent where further rock fissure break-up and rock block ejection can no longer take place (Bollaert and Schleiss 2003a).

An empirical formula proposed by Mason and Arumugam (1985) is of particular interest due to exhaustive data sets used from 26 prototype cases and 47 physical models with erodible beds:

(1) $\quad Y=\alpha \frac{H^{\alpha_{1}} q^{\alpha_{2}} h^{\alpha_{3}}}{g^{\alpha_{4}} d_{m}^{\alpha_{5}}}$

where $Y$ is the depth corresponding to the ultimate scour, which is the sum of the initial depth $h$ relative to the original riverbed and the scour depth $t_{c}, H$ is the hydraulic head determined by the difference between the reservoir and tailwater levels, $q$ is the discharge rate, $g$ is the gravitational acceleration, $d_{\mathrm{m}}$ is the mean particle or rock size, $\alpha=6.42-3.1 H^{0.10}, \alpha_{1}=0.15-H / 200, \alpha_{2}=0.60$ $-H / 300, \alpha_{3}=0.15, \alpha_{4}=0.30$, and $\alpha_{5}=0.10$. Although eq. (1) does not consider the physical processes involved in the scouring phenomenon, it has the merit of using the most important parameters in a straightforward manner and is still very used for a first estimation of the scour depth in the engineering practice.

Later, to account for the effect of air entrainment, Mason (1989) proposed a modification to eq. (1), this time only considering

Received 29 May 2015. Accepted 19 November 2015.

R. Duarte and A.J. Schleiss. Laboratory of Hydraulic Constructions (LCH), Ecole Polytechnique Fédérale de Lausanne (EPFL), Station 18, CH-1015 Lausanne, Switzerland.

A. Pinheiro. CEHIDRO, Instituto Superior Técnico, Universidade de Lisboa, Av. Rovisco Pais 1049-001 Lisbon, Portugal.

Corresponding author: Rafael Duarte (email: rafael.duarte@alumni.epfl.ch). 
Fig. 1. Definition sketch of plunging jets showing jet flow streamlines and time-averaged pressure distribution around a block embedded on a flat bottom (left) and a confined bottom (right).

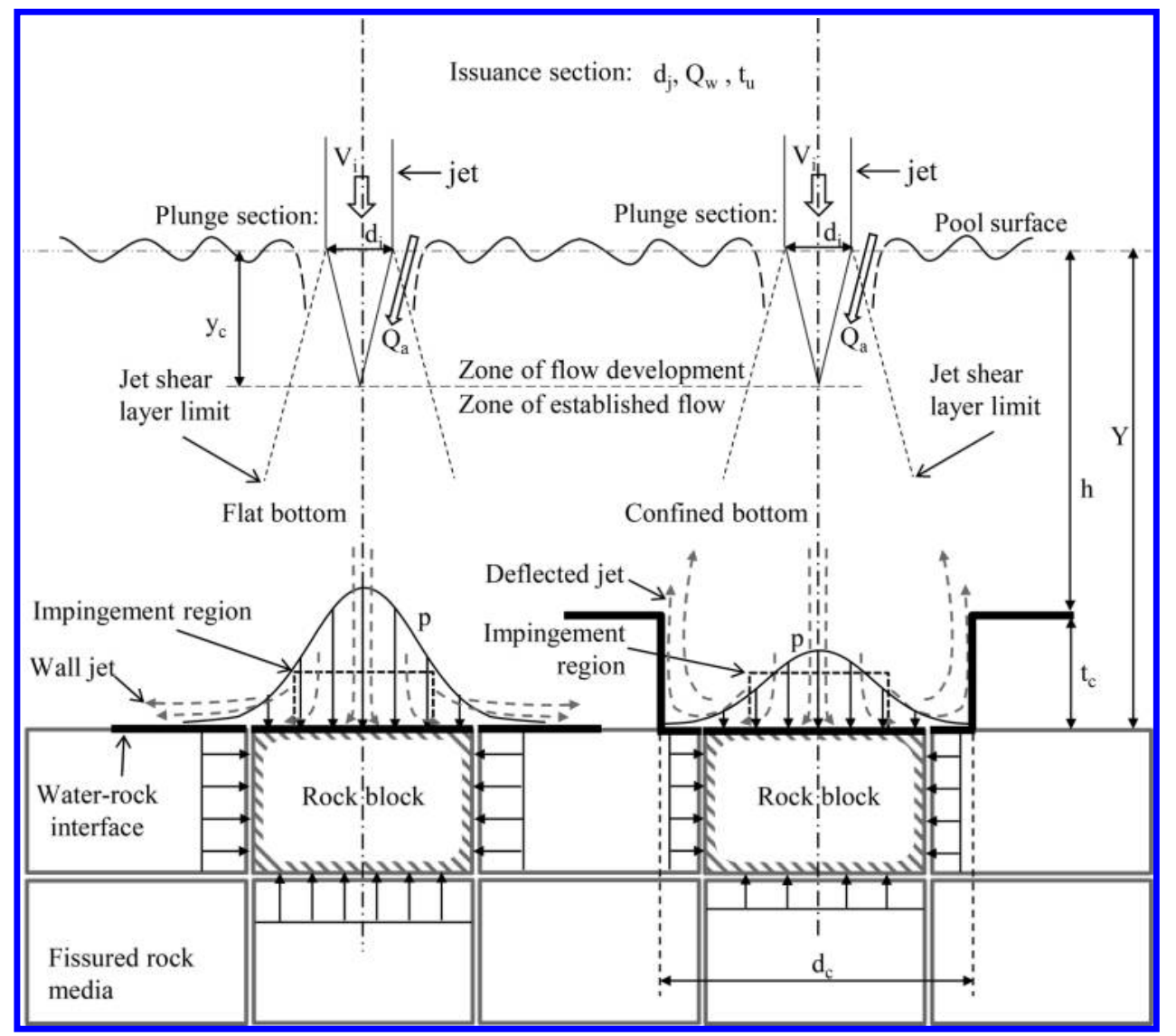

model tests on erodible beds formed with loose granular sediments:

$$
Y=\alpha \frac{(1+\beta)^{\alpha_{1}} q^{\alpha_{2}} h^{\alpha_{3}}}{g^{\alpha_{4}} d_{\mathrm{m}}^{\alpha_{5}}}
$$

where $\beta$ is the jet aeration provided at the plunge section, or the air-to-water ratio, defined as the entrained air discharge $Q_{\mathrm{a}}$ divided by the jet water discharge $Q_{w}$. The fitting process, for model results only, led to constant parameters, $\alpha=3.39, \alpha_{1}=0.30, \alpha_{2}=$ $0.60, \alpha_{3}=0.16, \alpha_{4}=0.30$, and $\alpha_{5}=0.06$. Although the physical justification for replacing the hydraulic head $H$ by the jet aeration $\beta$ as a parameter for scour assessment is questionable, it can give a reasonable upper bound for the ultimate scour depth (Bollaert 2002).

To evaluate the dynamic pressures acting on a rock mass, a solid but fissured media has to be considered instead of loose sediments. Systematic experiments using high-velocity jets in a large facility were performed by Bollaert and Schleiss (2003b), Manso et al. (2007), Federspiel (2011), and Duarte et al. (2015) for pools with a flat bottom and by Manso (2006) and Manso et al. (2009) for confined pool bottoms. These researches conducted in the Laboratory of Hydraulic Constructions (LCH) of the Ecole Polytechnique Fédérale de Lausanne (EPFL) developed a physically-based description of rock scour. Also, by establishing their investigations on near-prototype jet velocities and turbulence, scale effects from the experimental results are avoided. Finally, pressure fluctuations and transient pressures inside the fissures are considered for the correct assessment of the stability of rock blocks. It has been shown that the hydraulic fracturing of rock joints is the result of one of two possible mechanisms: brittle failure of rock joints, generated by short-duration pressure peaks, or fatigue resulting from cyclic loadings.

Compared to the simpler flat-bottom case, the impingement of a jet into a plunge pool with ideal confinement can be characterized by a confinement diameter $d_{c}$ and a pool depth $Y$ comprising the sum of the initial pool depth $h$ relative to the original riverbed and the scour depth $t_{c}$ (Fig. 1). Manso (2006) assessed dynamic pressures acting on the water-rock interface and inside a closedend fissure on the bottom of a plunge pool with nine different geometries, including one flat-bottom case and eight laterally confined configurations. He noted that the pool bottom geometry induces coherent flow patterns (Fig. 1), which strongly influence jet dissipation and air bubble penetration. The confined pool deflects the jet back towards the pool surface. The upward currents accentuate jet development and jet velocity decay, resulting in less energy reaching the pool bottom (Manso et al. 2009).

This study is developed in the frame of the previously cited researches of the LCH-EPFL with the objective of providing a comprehensive and physically-based description of rock scour. The main objective is to investigate the influences of pool bottom confinement and jet aeration simultaneously, in a more complex but realistic scenario. For such, a laterally confined pool on the dynamic pressures acting in a 3D open-end fissure around a free or fixed rock block impacted by aerated high-velocity jets was assessed experimentally.

\section{Physical model tests}

The experiments were carried out in a large facility (Fig. 2) built at the LCH-EPFL. Circular jets were issued vertically from a $d_{\mathrm{j}}=$ $72 \mathrm{~mm}$ diameter cylindrical nozzle. An air discharge $Q_{\mathrm{aa}}$ was 
Fig. 2. View of the experimental facility with confined bottom and detail of the instrumented block with the position of the pressure transmitters.

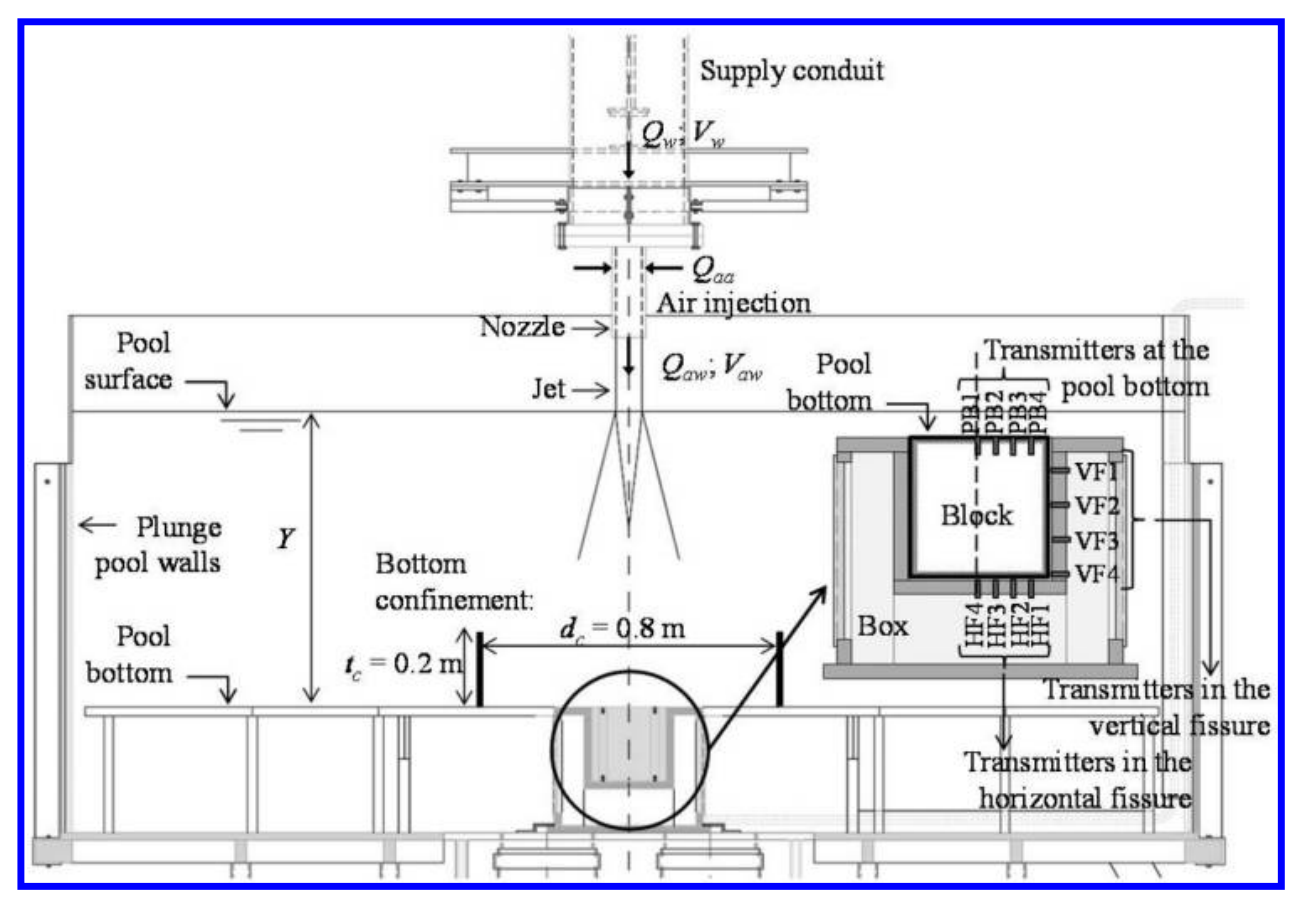

pumped into the nozzle through six small orifices to produce aerated water jets at the issuance section (Duarte 2013).

The generated air-water jet discharges $Q_{\mathrm{aw}}$ varied from 30 to $90 \mathrm{~L} / \mathrm{s}$. The corresponding velocities of the air-water jets at the issuance section $V_{\text {aw }}$ varied from 7.4 to $22.1 \mathrm{~m} / \mathrm{s}$. Four different values of jet aeration at the nozzle outlet $\beta_{1}=Q_{\mathrm{aa}} / \mathrm{Q}_{\mathrm{w}}$ were tested: $23 \%$ (which corresponded to the maximum air discharge the compressed air system could provide and measure), 15,8 , and $0 \%$. In addition, there is relevant air entrainment at the plunge section, as illustrated in Fig. 1.

The turbulence intensities $T_{u}$ of the water jets immediately downstream of the issuance section were measured in the longitudinal direction by Manso et al. (2008). Turbulence intensity $T_{u}$ values of approximately $8 \%$ for the lower jet velocities, reducing asymptotically to values between 4 and 5\% for high jet velocities, were observed. Hence, the experimental jets present nearprototype velocities and turbulence characteristics. Scale effects are thus minimized, and the spectral content of the pressure signals can be accurately reproduced (Bollaert and Schleiss 2003b).

The pool depth $Y$ was either 30,50 or $80 \mathrm{~cm}$, corresponding to relative pool depths $Y \mid d_{j}$ of $4.2,6.9$, and 11.1, respectively. This range of pool depth values allowed the reproduction of core jets and developed jets reaching the bottom. Lateral confinement was simulated by a $0.8 \mathrm{~m}$ diameter steel cylinder $\left(d_{\mathrm{c}} / d_{\mathrm{j}}=11.1\right.$, Fig. $\left.3 b\right)$ and compared to a reference flat-bottom case. This confinement corresponds to the "intermediate pool" tested by Manso et al. (2009). A rock block embedded on the pool bottom was represented by a metallic system composed of a box and a block (Fig. 3a). The cubic block with $20 \mathrm{~cm}$ sides was inserted into a box, whose dimensions provided a $1 \mathrm{~mm}$ thick 3D fissure between the block and the cavity, which was kept constant by lateral guides. The center of the block was aligned with the jet centerline, reproducing an axisymmetric configuration. The block was either fixed inside the cavity or free to move in the vertical direction. The test conditions are summarized in Table 1.

Twelve Kulite HKM-375M-17-BAR-A pressure transducers were uniformly flush-mounted along one half of the block (PB1 to PB4; VF1 to VF4; HF1 to HF4, Fig. 2). The pressure transducers were calibrated by Federspiel (2011) using a reference transducer, and calibration checks were performed three times on the experimen- tal facility during the present study. In all occasions the pressure versus Volt relationships were the same and matched the supplier's calibration curves. The dynamic pressures were measured with an acquisition frequency of $1 \mathrm{kHz}$. For each test run, 65536 samples were obtained. To ensure repeatability, each test run was performed three times (Duarte et al. 2013).

\section{Results and discussion}

General behavior of the jet and induced flow patterns

According to Beltaos and Rajaratnam (1977), the impingement of a jet on a flat obstacle perpendicular to its centerline is composed of three distinct regions, namely $(i)$ the free jet region, where the jet dissipates by shear with the surrounding fluid independently from the obstacle; (ii) the impingement region, where the jet is slowed abruptly by the presence of the obstacle, causing a pressure build-up around the stagnation point, which is the intersection of the jet centerline with the pool bottom; and (iii) the wall jet region, a consequence of mass conservation at stagnation. Hence, the vertical jet is deflected, creating a flow parallel to the obstacle.

The wall jet pulls the flow farther from the diffusive shear layer. At some distance of the stagnation point, where the energy of the wall jet has also dissipated, the recirculating currents in the pool make the flow rise slowly towards the surface. A laterally confined pool alters this behavior by deflecting the wall jet upwards before its energy is completely dissipated. This induces shear between the downward and upward currents and contributes to jet dissipation.

In Fig. $4 a$, an upward deflection of the wall jet, as a consequence of pool bottom confinement, is clearly visible due to the flow of the entrained air bubbles. In Fig. $4 b$, jet ejections from the pool surface can be seen. The latter is more pronounced for relatively shallow pools and high jet velocities.

\section{Dynamic pressures around the block}

The time-averaged pressures and the pressure fluctuations around the block were analyzed. By considering the issued jet as a homogeneous mixture of air and water, the mean density of the jet at issuance is 
Fig. 3. Photos of (a) detail of the instrumented block being inserted into the cavity and $(b)$ experimental facility with confinement cylinder and instrumented block installed on the bottom.

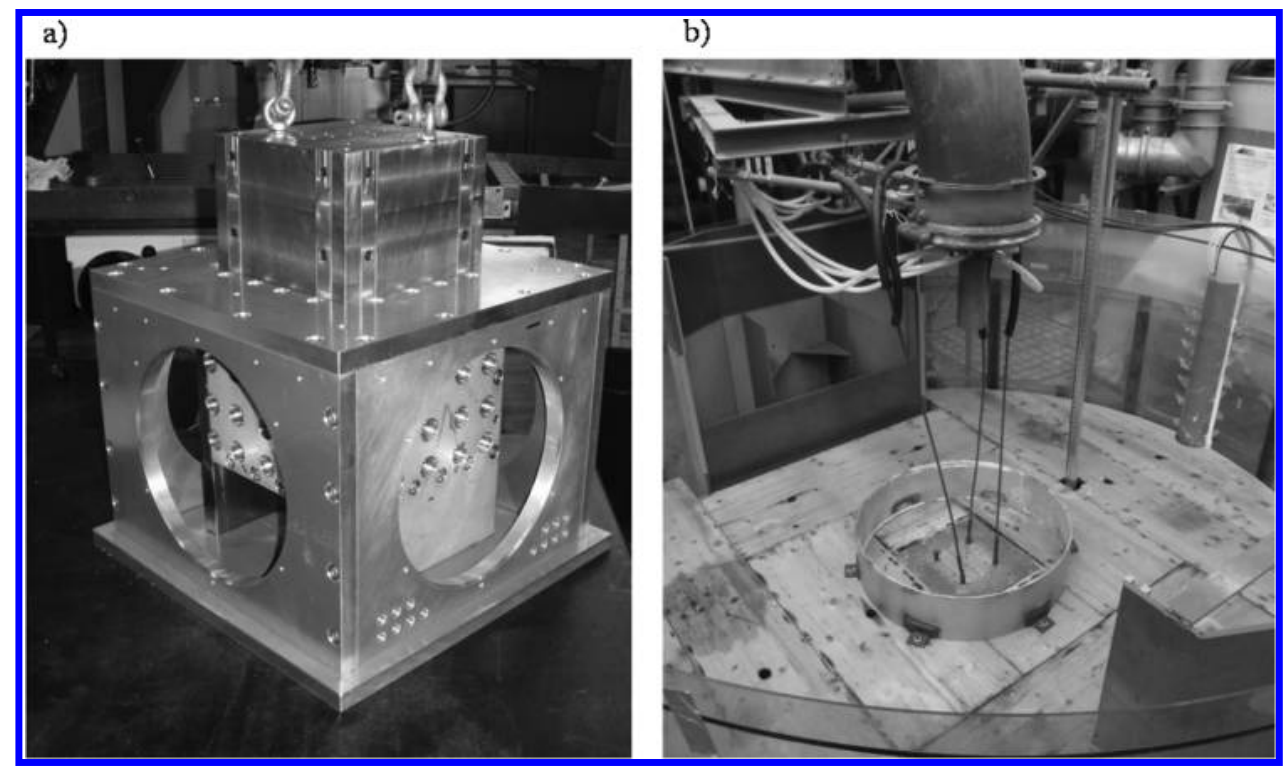

Table 1. Tested configurations.

\begin{tabular}{lllllll}
\hline $\begin{array}{l}\text { Impact } \\
\text { position }\end{array}$ & Impact type & $\begin{array}{l}\text { Block } \\
\text { movement }\end{array}$ & $\begin{array}{l}\text { Bottom } \\
\text { geometry }\end{array}$ & $\begin{array}{l}\text { Pool depth } \\
Y(\mathrm{~cm})\end{array}$ & $\begin{array}{l}\text { Total jet discharge } \\
Q_{\mathrm{aw}}(\mathrm{L} / \mathrm{s})\end{array}$ & $\begin{array}{l}\text { Jet aeration at } \\
\text { issuance } \beta_{1}(\%)\end{array}$ \\
\hline Centered jets & Plunging jets & Fixed & $\begin{array}{l}\text { Flat } \\
\text { Confined }\end{array}$ & $30,50,80$ & $30,40,50,60,70,80,90$ & $0,8,15,23$ \\
& & Free & $\begin{array}{l}\text { Flat } \\
\text { Confined }\end{array}$ & & & \\
& & & & & \\
\end{tabular}

Fig. 4. Photos of (a) detail of the jet-flow-induced patterns in the plunge pool $\left(V_{\mathrm{aw}}=7.4 \mathrm{~m} / \mathrm{s}, \beta_{1}=0 \%\right)$ and $(b)$ jet geyser-like flow ejections $\left(V_{\mathrm{aw}}=22.1 \mathrm{~m} / \mathrm{s}, \beta_{1}=0 \%\right)$.

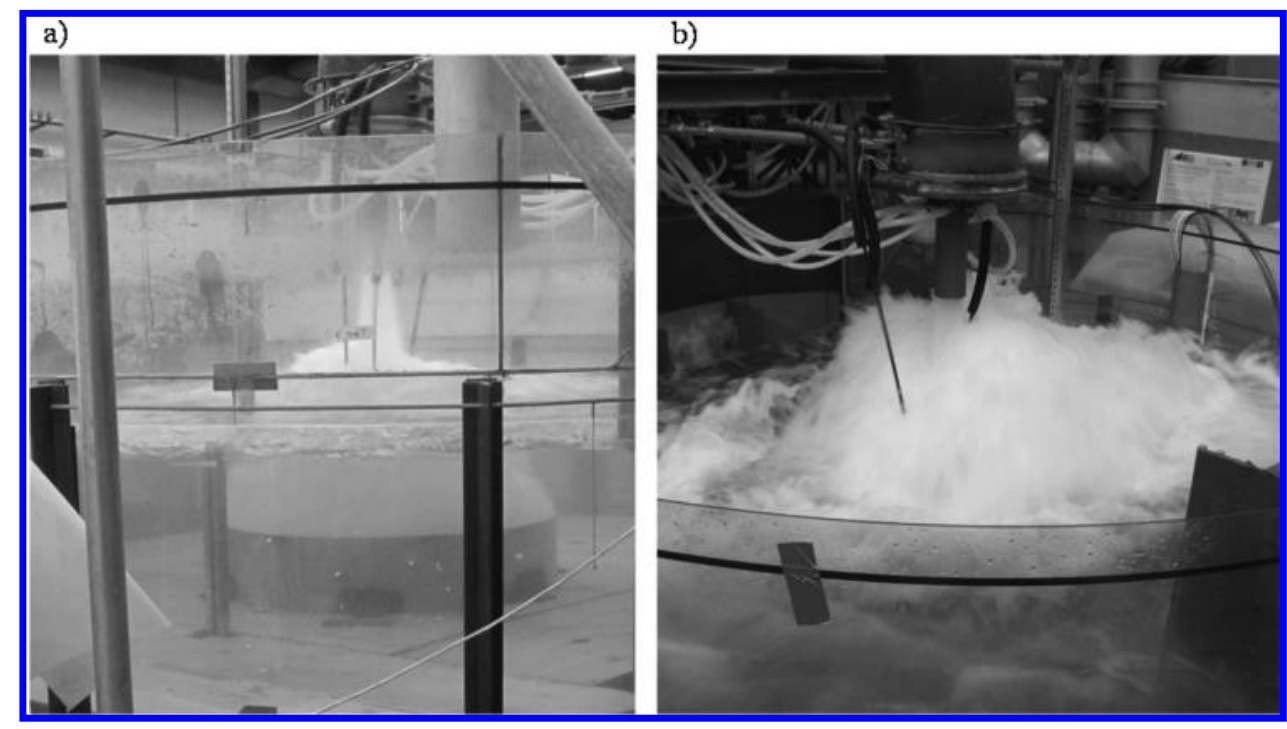

$$
\rho_{\mathrm{aw}}=\frac{1}{1+\beta_{1}} \rho_{\mathrm{w}}+\frac{\beta_{1}}{1+\beta_{1}} \rho_{\mathrm{a}}
$$

where $\rho_{\mathrm{w}}$ and $\rho_{\mathrm{a}}$ are, respectively, the water and air densities.

Non-dimensional pressure coefficients for the time-averaged pressures $C_{\mathrm{p}}$ and for the pressure fluctuations $C_{\mathrm{p}}$, were computed at each transducer position on the block using the kinetic energy per unit volume of the jet at the plunge section as the scaling parameter.
(4) $\quad C_{\mathrm{p}}=\frac{p_{\text {mean }}-\rho_{\mathrm{w}} g Y^{\prime}}{1 / 2 \rho_{\mathrm{aw}} V_{\mathrm{i}}^{2}}$

(5) $\quad C_{\mathrm{p}}^{\prime}=\frac{p^{\prime}}{\frac{1}{2} \rho_{\mathrm{aw}} V_{\mathrm{i}}^{2}}$

where $p_{\text {mean }}$ and $p$ ' are, respectively, the time-averaged pressure and the RMS of the pressure fluctuations, $Y^{\prime}$ is the vertical distance 
Fig. 5. Time-averaged pressure coefficient $C_{\mathrm{p}}$ around the fixed block for an issuance jet velocity $V_{\text {aw }}=22.1 \mathrm{~m} / \mathrm{s}$ and different relative pool depths; $(a) Y\left|d_{\mathrm{j}}=4.2 ;(b) Y\right| d_{\mathrm{j}}=6.9 ;(c) Y \mid d_{\mathrm{j}}=11.1$; for flat bottom with $\beta_{1}=0 \%$ (white bars) and $\beta_{1}=23 \%$ (black bars); as well as for confined bottom with $\beta_{1}=0 \%$ (hatched bars) and $\beta_{1}=23 \%$ (grey bars).

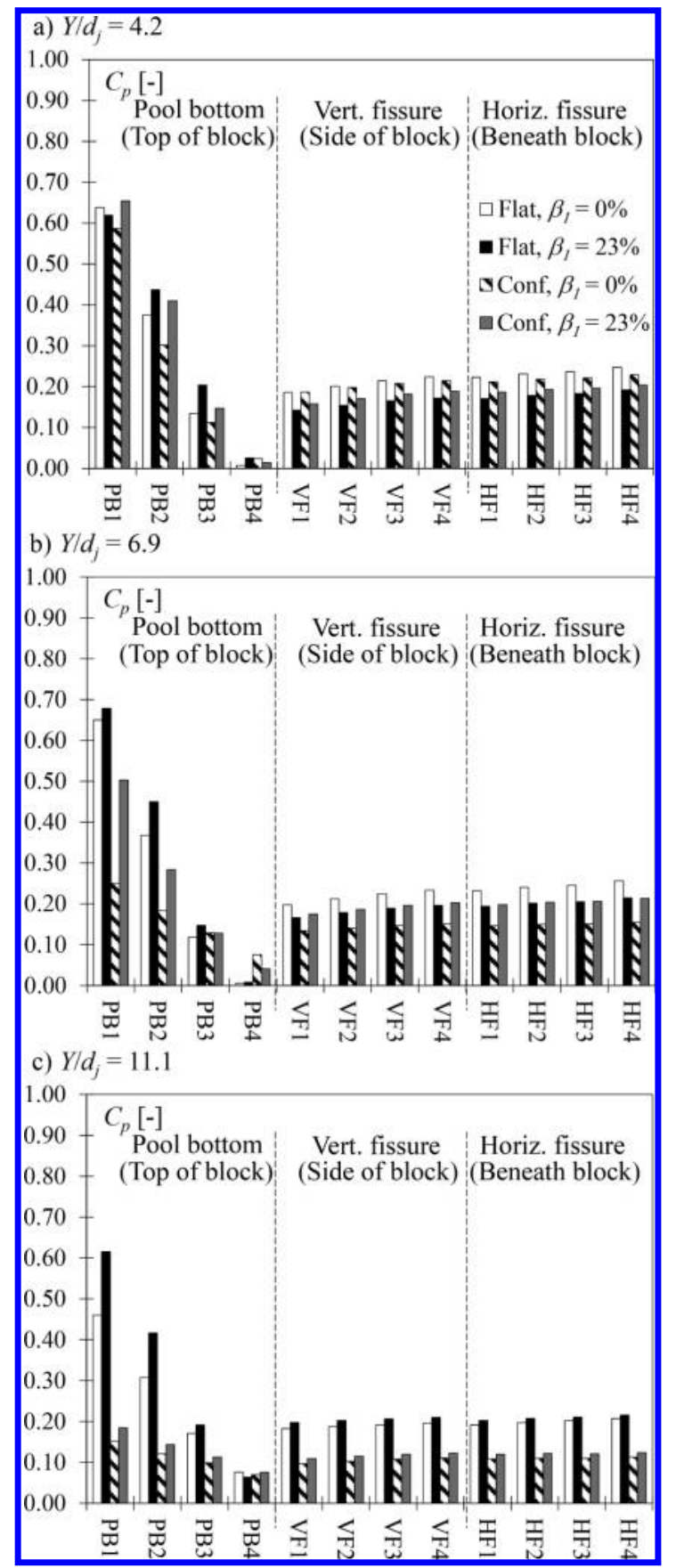

between the pool surface and the pressure transducer, and $V_{\mathrm{i}}$ is the velocity of the jet at the plunge section, considering the gravity acceleration during the fall distance.

\section{Influence of pool confinement and jet aeration}

For the case of a fixed block and the highest tested jet velocity $\left(V_{\mathrm{aw}}=22.1 \mathrm{~m} / \mathrm{s}\right)$ and for the three tested relative pool depths, $C_{\mathrm{p}}$ and $C_{p}$, values are represented in Figs. 5 and 6 . The flat and confined-bottom configurations and non-aerated $\left(\beta_{1}=0 \%\right)$ and aerated jets $\left(\beta_{1}=23 \%\right)$ are compared.
Fig. 6. Pressure fluctuation coefficient $C^{\prime}{ }_{\mathrm{p}}$ around the fixed block for an issuance jet velocity $V_{\text {aw }}=22.1 \mathrm{~m} / \mathrm{s}$ and different relative pool depths; (a) $Y \mid d_{\mathrm{j}}=4.2$; (b) $Y / d_{\mathrm{j}}=6.9$; (c) $Y \mid d_{\mathrm{j}}=11.1$; for flat bottom with $\beta_{1}=0 \%$ (white bars) and $\beta_{1}=23 \%$ (black bars); as well as for confined bottom with $\beta_{1}=0 \%$ (hatched bars) and $\beta_{1}=23 \%$ (grey bars).

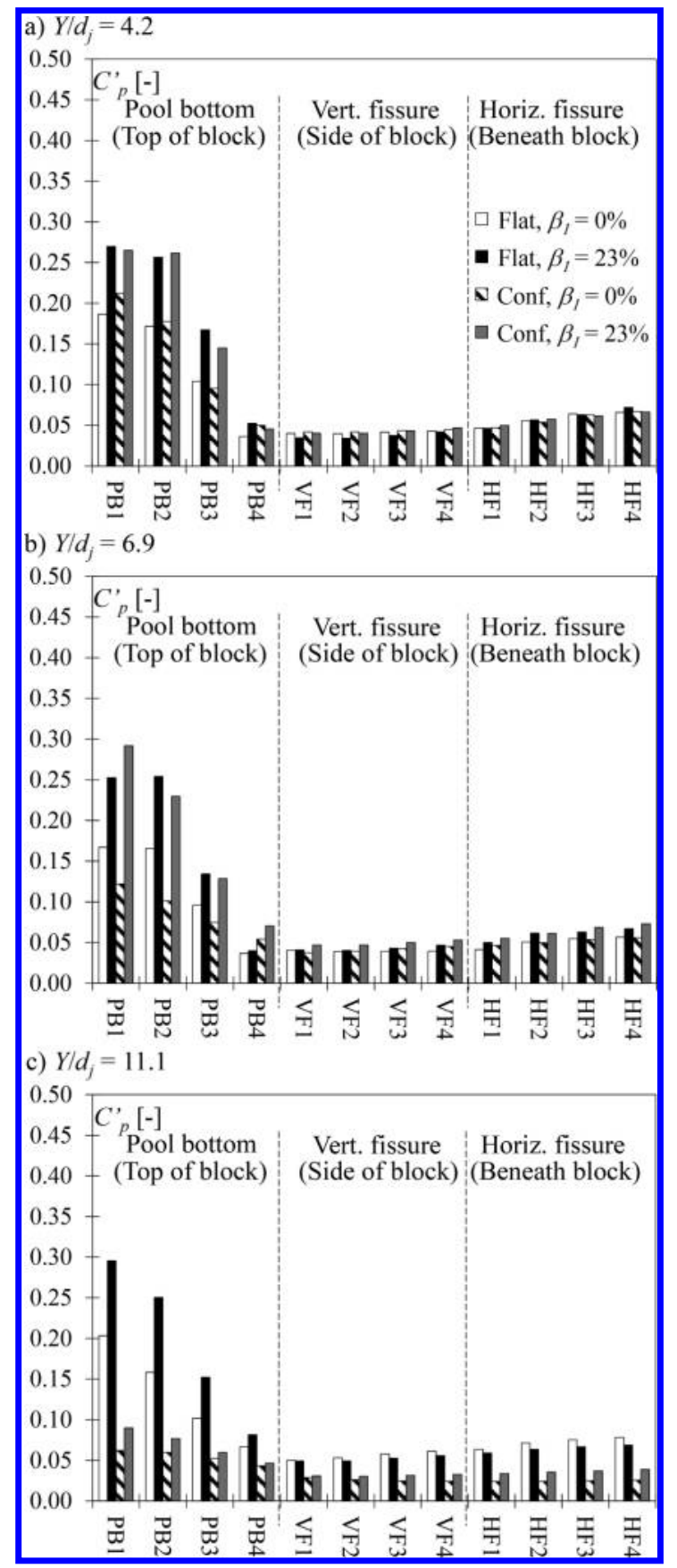

The general trends for the distribution of both $C_{\mathrm{p}}$ and $C_{\mathrm{p}}$ throughout the block have been explained by Duarte et al. (2015). Both parameters present Gaussian distributions on the pool bottom (top of the block), similar to the velocity distribution in a cross section of a jet impinging in a pool. Inside the fissures, the time-averaged pressure and pressure fluctuation coefficients slowly increase toward the center of the joint (HF4). In such a symmetric case, this increase of the pressure coefficients inside the fissure is caused by the superposition of the pressure waves, reaching its maximum in the central position of the fissure. 
In Figs. 5 and 6, it can be seen that the influences of the jet aeration and of the confined bottom strongly depend on the relative pool depth. The influence of entrained air was discussed in detail in Duarte et al. (2015). It was highlighted that the air bubbles have two opposing effects on the resulting pressures. On one hand, the pressures are reduced as a consequence of the lower momentum of aerated jets, due to their lower density. On the other hand, jet velocity decay along the pool depth is reduced by the entrained air bubbles, which increases the pressures on the bottom, especially close to stagnation. The latter effect is evidently stronger in relatively deep pools.

The reduction of $C_{\mathrm{p}}$ (Fig. 5) due to pool confinement was stronger for a deep pool $\left(Y / d_{j}=11.1\right)$ but was almost inexistent for a shallow pool $\left(Y \mid d_{\mathrm{j}}=4.2\right)$. This is explained by the effect of the shear between upward and downward currents on the resulting pressures, which depend on the pool depth. The pool depth governs the length along which the shear stress dissipates the jet energy.

Similar behavior was observed for $C_{\mathrm{p}}$ (Fig. 6). In the confinedbottom case, the deeper the pool, the more the pressure fluctuations were reduced. For the flat-bottom case, $C_{p}$, values were higher for the deep pool $\left(Y \mid d_{j}=11.1\right)$, in agreement with Bollaert and Schleiss (2005) and Manso et al. (2007), who found that a developed jet impact on the bottom produces higher pressure fluctuations than a core jet.

The influences of pool confinement and jet aeration on $C_{p}$ for the whole set of tested jet velocities and pool depths are shown in Fig. 7 at the intersection of the jet centerline with the water-rock interface (stagnation point, PB1, Fig. 2). Two different regions can be clearly distinguished, corresponding to a developed jet impact or a core jet impact on the bottom.

A core jet impact on the bottom occurs when the core development length $y_{c}$ is greater than the existing pool depth $Y$. This yields a compact jet core impacting directly on the bottom, which results in high time-averaged pressures and relatively low pressure fluctuations. On the other hand, a developed jet impact is observed when $y_{c}<Y$ (Fig. 1 is an example). The resulting timeaveraged pressures are lower due to the dissipation of the jet along its centerline.

Duarte et al. (2013) pointed out that the limit between a core jet impact and a developed jet impact depends on both the pool depth and jet velocity. Figure 7 (all cases) shows that, for relatively low velocities, $C_{\mathrm{p}}$ increases with a concave function of the jet velocity. This corresponds to a developed jet impact on the bottom, being the core of the jet previously disintegrated along the shear layer. For a deep pool $\left(\mathrm{Y} / d_{\mathrm{j}}=11.1\right)$, only developed jet impact was observed because the jet core never reaches the bottom (Fig. 7c). Indeed, the maximum core length found for high jet velocities was $y_{\mathrm{c}}=7.8 d_{\mathrm{i}}$ for plunging jets, which is coherent with the current pressure results.

For the remaining shallower pool depths $\left(Y / d_{j}=4.2\right.$ and 6.9, Figs. $7 a$ and $7 b$ ), a change is evident at approximately $V_{\text {aw }}=15 \mathrm{~m} / \mathrm{s}$, where an increasing tendency of $C_{\mathrm{p}}$ at lower jet velocities shifts to a convex decreasing tendency at higher jet velocities, corresponding to core impacts on the bottom. The maximum $C_{\mathrm{p}}$ values are observed at the intersection of the two regions. This means that the transitional jets where $y_{c}=Y$ are the most efficient in terms of converting the kinetic energy of the jet into time-averaged pressures acting on the bottom at stagnation. However, in Fig. 7, the outer bounds are only indicative of the behavior of the timeaveraged pressure coefficient evolution with increasing jet velocity. They correspond only approximately to the zones for core and developed jet impacts and the transition between the two.

The combined influences of pool bottom confinement and jet aeration can be clearly noticed and confirm the assumptions made previously. A confined bottom resulted in lower $C_{\mathrm{p}}$ values at stagnation for jets of similar velocity and aeration. The deeper the pool, the stronger the reduction of the confined case compared to the flat one. Reductions of $C_{\mathrm{p}}$ due to pool bottom confinement
Fig. 7. Time-averaged pressure coefficient $C_{\mathrm{p}}$ at stagnation versus the issuance jet velocity $V_{\text {aw }}$ for different relative pool depths; (a) $Y / d_{\mathrm{j}}=4.2 ;(b) Y / d_{\mathrm{j}}=6.9 ;(c) Y \mid d_{\mathrm{j}}=11.1$; flat bottom with $\beta_{1}=0 \%$ (ם), $\beta_{1}=8 \%(\Delta) ; \beta_{1}=15 \%(\bullet)$ and $\beta_{1}=23 \%(\diamond)$; confined bottom with $\beta_{1}=0 \%(\square), \beta_{1}=8 \%(\Delta), \beta_{1}=15 \%(\bigcirc)$ and $\beta_{1}=23 \%(224)$; and indicative outer bounds (dashed lines).

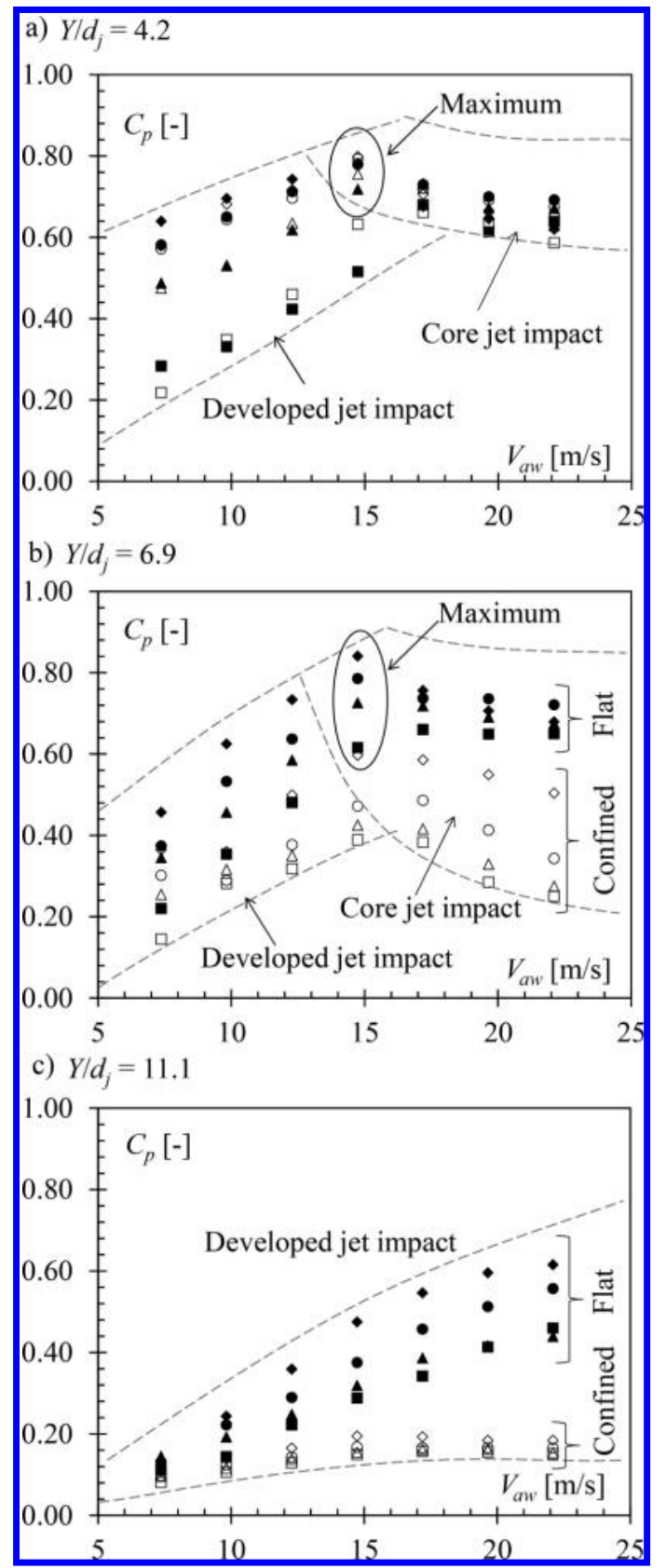

were zero or minimal for the shallow pool $\left(Y / d_{\mathrm{j}}=4.2\right.$, Fig. $\left.7 a\right)$. Given similar jets, those with higher aeration produced higher $C_{\mathrm{p}}$ values. The differences increased with the pool depth. Hence, both the effects of pressure reduction due to jet confinement and pressure rise due to the lower jet dissipation rate of aerated jets close to stagnation are exacerbated by an increasing pool depth.

\section{Differences between fixed and free block}

When the block is free to move in the vertical direction inside the cavity, pressure is attenuated inside the fissures due to block vibrations. The pressures acting inside the fissures are the result of the excitation provided by the energy signals at the fissure 
Fig. 8. Time-averaged pressure coefficient $C_{\mathrm{p}}$ at the fissure entrance (VF1) versus jet velocity $V_{\text {aw }}$; non-aerated jets $\left(\beta_{1}=0 \%\right)$; for a fixed block with $Y\left|d_{\mathrm{j}}=11.1(\diamond) ; Y\right| d_{\mathrm{j}}=6.9(\bigcirc)$ or $Y \mid d_{\mathrm{j}}=4.2(\square)$; and for a free block with $Y\left|d_{\mathrm{j}}=11.1(\diamond) ; Y\right| d_{\mathrm{j}}=6.9(\bullet)$ or $Y \mid d_{\mathrm{j}}=4.2(\square) ;(a)$ flat bottom; (b) confined bottom.

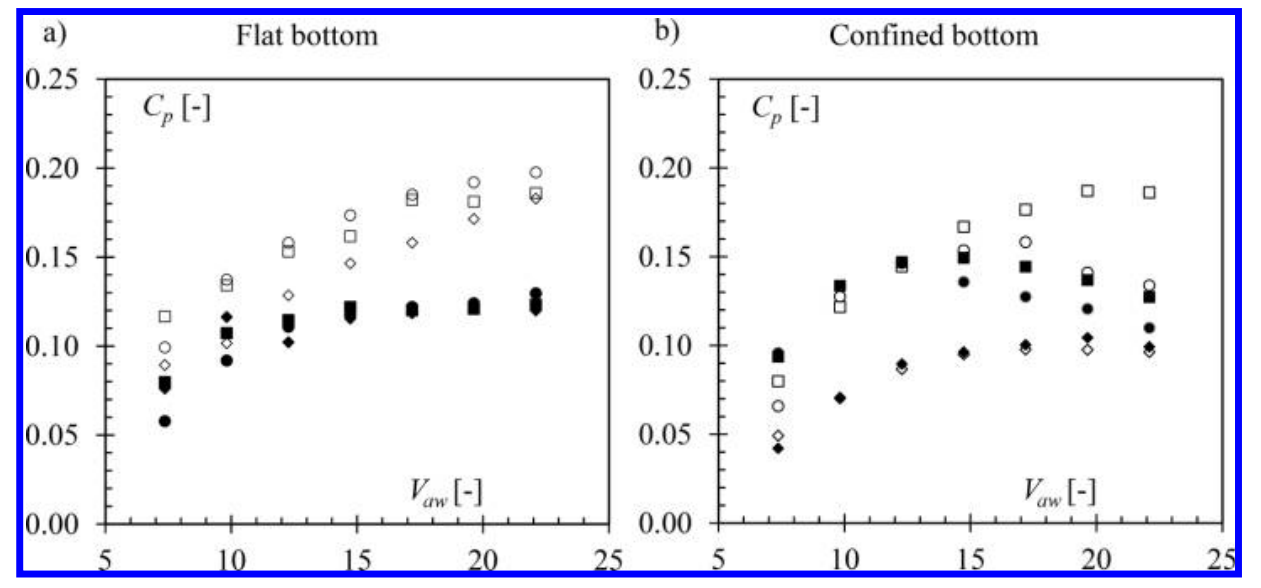

entrances at the water-rock interface and by pressure wave propagation inside the 3D joint. Hence, the dynamic pressures inside the fissures were analyzed at the position VF1, close to the fissure entrance.

Figure 5 shows that jets impinging on the center of the block produced time-averaged pressure coefficients $C_{\mathrm{p}}$ close to the fissure entrance that are always higher inside the fissure (VF1) than at the pool bottom (PB4), where a wall jet is formed. This confirms that the fissure is excited by a combination of both dynamic pressures and wall jet. Then, the increase of mean pressures, pressure fluctuations, and extreme pressure values towards the center of the fissure (HF4) is a result of the superposition of pressure waves, even though this increase is too small to produce a positive dynamic uplift force.

Figure 8 shows $C_{\mathrm{p}}$ values at the fissure entrance (VF1) for nonaerated jets impinging on a flat and a confined bottom with different relative pool depths. A comparison is made between fixed and free blocks.

For the flat-bottom case (Fig. 8a), the differences between the time-averaged pressure coefficients $C_{\mathrm{p}}$ for fixed and free blocks become significant for jet velocities $V_{\text {aw }}>11 \mathrm{~m} / \mathrm{s}$. It is likely that above this limit, the block vibrations for the flat-bottom case are relevant. While the $C_{\mathrm{p}}$ values for a fixed block increase continuously, for a free block they reach a limit at approximately 0.12 . For the confined case (Fig. $8 b$ ), the behavior of $C_{\mathrm{p}}$ is strongly dependent on the relative pool depth, for the reasons stated before. For a relatively shallow pool $\left(Y / d_{j}=4.2\right)$, a fixed block generates $C_{\mathrm{p}}$ values very similar to those for a flat bottom. A pressure attenuation can be observed for jet velocities above approximately $14 \mathrm{~m} / \mathrm{s}$. On the other hand, for the deep pool $\left(Y \mid d_{j}=11.1\right)$, fixed and free blocks result in similar $C_{\mathrm{p}}$ values, because block vibrations are insignificant in this case.

The $C_{\mathrm{p}}{ }_{\mathrm{p}}$ results close to the fissure entrance, at VF1, are shown in Fig. 9, under the same configurations used for $C_{\mathrm{p}}$. For the flatbottom case, $C_{\mathrm{p}}$, decreases when the jet velocity increases for the deeper pools $\left(Y \mid d_{\mathrm{j}}=6.9\right.$ and $\left.Y \mid d_{\mathrm{j}}=11.1\right)$, while $C^{\prime}{ }_{\mathrm{p}}$ increases slightly as a function of the jet velocity for the shallow pool $\left(Y \mid d_{j}=4.2\right)$. The free block results in a small reduction of the $C_{\mathrm{p}}$, values. For the confined-bottom case, the $C_{\mathrm{p}}$, results are concentrated in a narrow range, between 2 and 5\%, for all the tested jet velocities. The higher fluctuations observed for lower jet velocities and deep pools are reduced for the flat-bottom case. This may be explained by the fact that the block moves so little, and consequently the differences between fixed and free blocks are minimal.

\section{Spectral contents of the pressure signals}

The power spectral densities (PSDs) of the pressure signals $P_{x x}$ were computed using fast Fourier transform (FFT) based on the Welch periodogram method. The signals, each composed of 65536 samples, were segmented into 64 blocks using a Hamming window and a $50 \%$ overlap.

The spectral content of the signals represents the energy of each frequency range and provides information about the flow features. In turbulent flows, each frequency is related to turbulent eddies of corresponding length (Chassaing 2000). In the case of impinging jets, the energy associated with each eddy size decays as a power function of the frequency (Bollaert and Schleiss 2003b).

\section{Influence of pool confinement and jet aeration}

Figure 10 shows the obtained spectral contents around the fixed block for a high-velocity jet $\left(V_{\mathrm{aw}}=22.1 \mathrm{~m} / \mathrm{s}\right)$, comparing the flat and the confined cases for the shallow pool $\left(Y \mid d_{j}=4.2\right)$ and the deep $\operatorname{pool}\left(Y / d_{\mathrm{j}}=11.1\right)$.

In general, the developed jet impact occurring in deep pools is characterized by a relatively large shear layer where turbulent energy is produced. This corresponds, for example, to the nearhorizontal spectral content at low frequencies, as shown in Fig. 10c. The limit between horizontal and inclined zones is representative of the largest length of the eddies in the jet shear layer. Smaller eddies produce almost no turbulent energy. This is represented by an inertial range of scales with a $-5 / 3$ decay slope in the spectral content (at the right side of the slope change in Fig. 10c).

On the other hand, core jet impact occurs in relatively shallow pools and is characterized by a thinner shear layer compared to developed jets. Turbulent energy is thus distributed across the whole range of frequencies, which is represented by a -1 decay slope (Fig. 10a). In both developed and core jet impacts, relevant resonance phenomena are observed inside the fissures. Due to symmetry, the amplification of the pressure waves is maximal at the center of the fissure (position HF4). The fundamental frequency $f_{\text {res }}=c /\left(2 L_{\mathrm{f}}\right)$, where $c$ is the wave celerity and $L_{\mathrm{f}}$ is the fissure length, for the whole open-end fissure around the block is represented as $f_{\text {res1. }}$. Due to important partial reflections in the horizontal part of the 3D fissure, a second fundamental frequency is also observed at positions HF2 and HF4 and is denoted as $f_{\text {res2 }}$.

The confined bottom configuration changes the structure of the turbulent flows. Comparing Fig. 10a with Fig. $10 \mathrm{~b}$ reveals that the original core jet spectrum, with a constant -1 decay, changed to a typical developed jet spectrum. A concentration of the turbulent energy at lower frequencies can be observed for the confined case, followed by typical inertial scales with a $-5 / 3$ slope decay. 
Fig. 9. Pressure fluctuation coefficient $C_{\mathrm{p}}$, at the fissure entrance (VF1) versus jet velocity $V_{\mathrm{aw}}$; non-aerated jets $\left(\beta_{1}=0 \%\right)$; for a fixed block with $Y \mid d_{\mathrm{j}}=11.1(\diamond) ; Y / d_{\mathrm{j}}=6.9(\bigcirc)$ or $Y \mid d_{\mathrm{j}}=4.2(\square)$; and for a free block with $Y \mid d_{\mathrm{j}}=11.1(\diamond) ; Y / d_{\mathrm{j}}=6.9(\bullet)$ or $Y \mid d_{\mathrm{j}}=4.2(\square) ;(a)$ flat bottom; $(b)$ confined bottom.

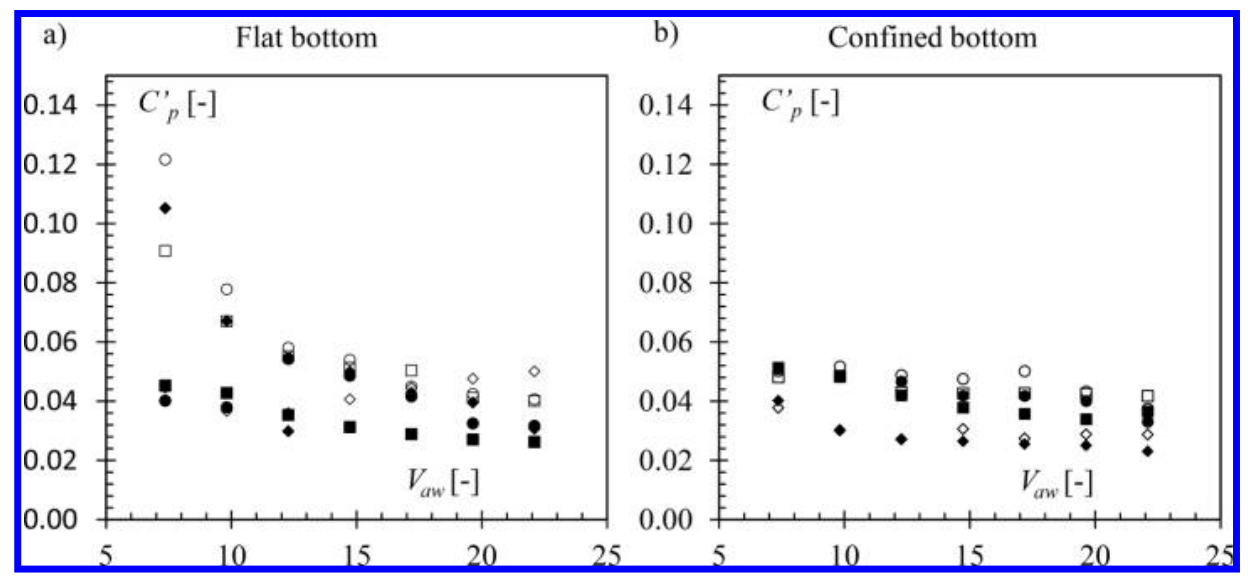

Fig. 10. PSD of the pressure fluctuations at selected positions on the fixed block; $V_{\mathrm{aw}}=22.1 \mathrm{~m} / \mathrm{s}$; for a shallow pool $\left(\mathrm{Y} / d_{\mathrm{j}}=4.2\right)$, non-aerated $\left(\beta_{1}=0 \%\right)$, with flat $(a)$ and confined bottom $(b)$, as well as for a deep pool $\left(Y / d_{\mathrm{j}}=11.1\right)$, non-aerated $\left(\beta_{1}=0 \%\right)$ with flat $(c)$ and confined bottom $(d)$, and for a shallow pool $\left(Y \mid d_{\mathrm{j}}=4.2\right)$, aerated $\left(\beta_{1}=23 \%\right)$ with flat $(e)$ and confined bottom $(f)$. [Colour online.]

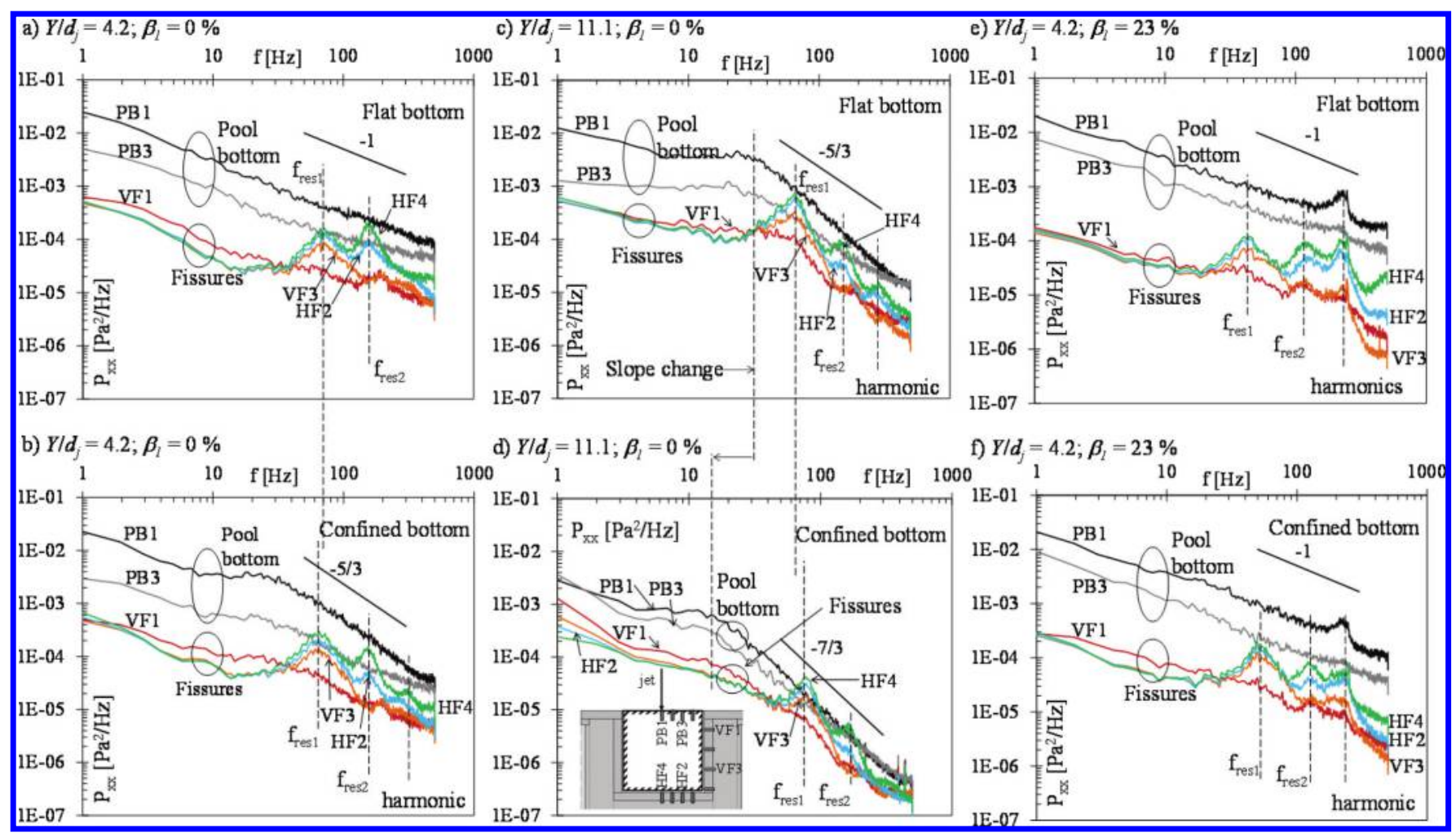

A concentration of turbulent energy at lower frequencies can also be seen when comparing the developed jet impinging on a flat bottom in Fig. 10c with the corresponding confined configuration in Fig. 10d. There is a significant shift of the slope change towards lower frequencies for the confined case. Additionally, for the confined case, the energy is transferred with a $-7 / 3$ decay slope in the inertial range of scales, instead of the $-5 / 3$ slope observed in the flat-bottom case.

Pool bottom confinement has negligible influence on the resonance frequencies inside the fissures, unlike the case of jet aeration (Duarte et al. 2015). The resonance frequency inside the fissures is a function only of the pressure waves' celerity and varies with the air concentration of the air-water flow and the fluid-structure interactions with the flow boundaries.
However, when aerated jets $\left(\beta_{1}=23 \%\right)$ impinge on the confined bottom, the previously observed concentration of spectral energy at lower frequencies is neutralized. This can be shown by comparing aerated high-velocity jets impinging on a flat bottom (Fig. 10e) or a confined bottom (Fig. 10f), which have similar spectral contents.

\section{Differences between fixed and free block}

Compared to a fixed block, a free block has two effects on the spectral content of pressure fluctuations. The overall spectral energy inside the fissures is lower due to the pressure attenuation that takes place for free blocks. Additionally, a free block has significant influence on the resonance frequencies and hence on the wave celerity of the pressure waves inside the joints. 
Fig. 11. PSD of the pressure fluctuations at selected positions around the block for a flat bottom with $\beta_{1}=8 \% ; V_{\mathrm{aw}}=22.1 \mathrm{~m} / \mathrm{s} ;$ for a fixed block with $(a)$ shallow pool $\left(Y / d_{j}=4.2\right)$ or $(b)$ deep pool $\left(Y / d_{j}=11.1\right)$; as well as for a free block with $(c)$ shallow pool $\left(Y / d_{j}=4.2\right)$ or $(d)$ deep pool $\left(Y / d_{j}=11.1\right)$. [Colour online.]

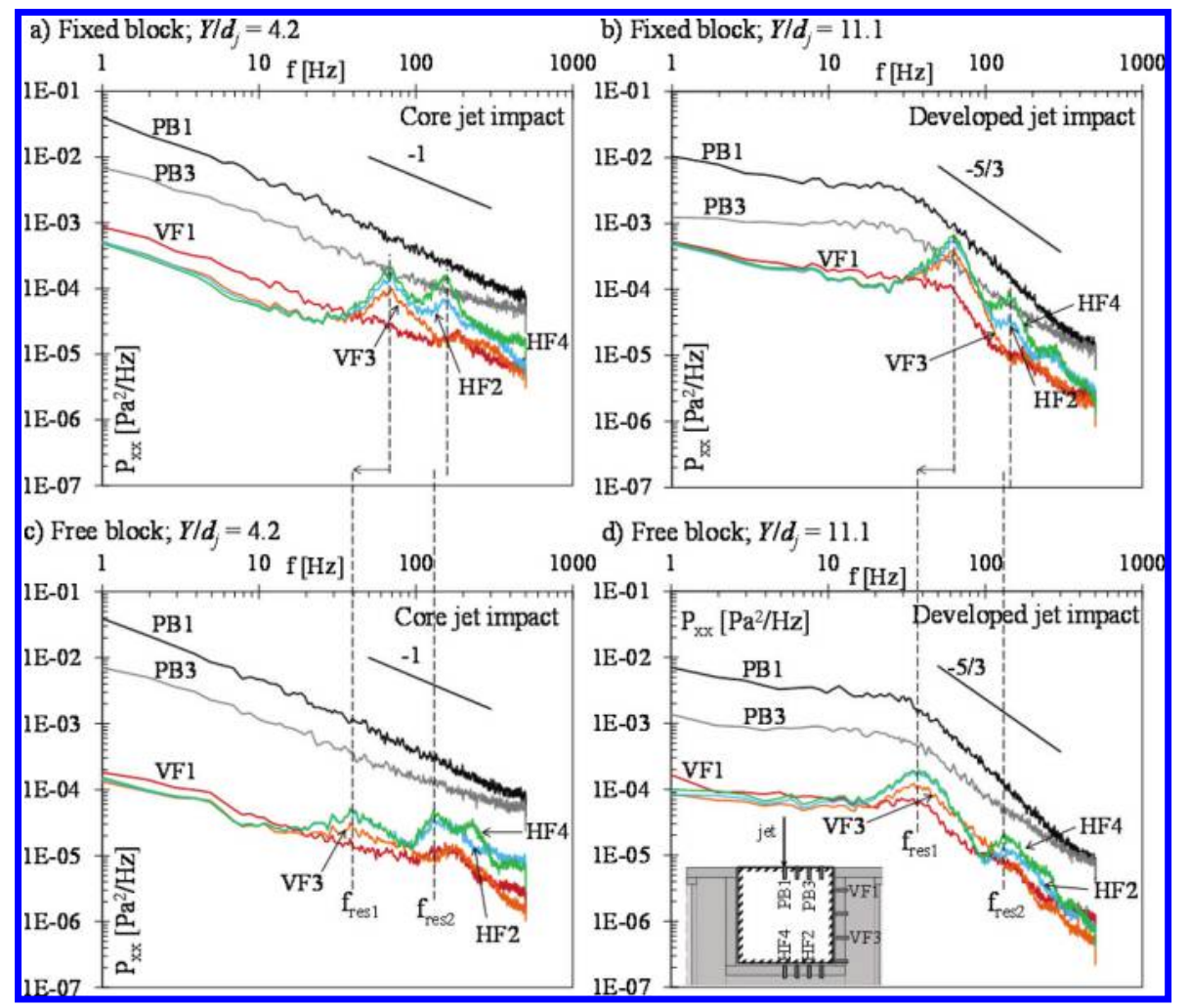

Figure 11 shows PSD estimates for fixed and free blocks and for shallow and deep pools. The resonance peaks inside the fissures observed for the fixed blocks are strongly dampened and shifted toward lower frequencies if the blocks are free to move. This results from the fluid-structure interactions between the dynamic pressures propagating inside the joints and the moving boundaries of the flow, which are the block faces.

The celerity of the pressure waves propagating on closed conduits depends on the elastic properties of the fluid and of the flow boundaries. This has been extensively studied for the waterhammer phenomenon inside pressure conduits (Ghidaoui et al. 2005; Hachem and Schleiss 2011; Halliwell 1963). Similarity exists with the case of pressure waves inside rock joints (Bollaert 2002). The pressure wave celerity is presented as a function of the fluid density $\rho_{\mathrm{aw}}$ and the bulk modulus of elasticity $K_{\mathrm{aw}}$, both hereby representing apparent properties of the air-water mixture, Young's modulus of elasticity of the pipe walls $E$ as well as the ratio between the conduit wall thickness $e_{\mathrm{c}}$ and diameter $D$. According to Ghidaoui et al. (2005), the celerity of a water-hammer propagating inside closed-conduits is defined by

$$
c=\sqrt{\frac{K_{\mathrm{aw}}}{\rho_{\mathrm{aw}}\left(1+K_{\mathrm{aw}} \times D / E e_{\mathrm{c}}\right)}}
$$

Comparisons with pressure waves propagating inside openended rock joints surrounding free or moderately interlocked rock blocks demonstrate that the wave celerity inside the fissures is reduced by both jet air entrainment and block vibrations. Nevertheless, this phenomenon will not be reproduced correctly by eq. (6), as an important component of the rock vibrations is due not to elastic deformations of the rock material but due to the displacement of the whole block as a solid body. Hence, the term $D / e_{\mathrm{c}}$ in eq. (6) may be replaced by a parameter $\psi$ representing an elastic joint condition (Chaudhry 2014), as in the following equation:

$$
c=\sqrt{\frac{K_{\mathrm{aw}}}{\rho_{\mathrm{aw}}\left(1+K_{\mathrm{aw}} \times \psi / E\right)}}
$$

\section{Conclusions}

The combined influences of pool bottom confinement and jet aeration on the pressures around a block inserted in a plunge pool bottom were assessed experimentally using near-prototype jet velocities. Recent experimental studies on the isolated effects of jet aeration (Duarte et al. 2015), pool geometry with closed-end fissures (Manso et al. 2009; Manso 2006), and open-end fissures on a flat bottom (Federspiel 2011) are thus completed with new insights.

A pool bottom confinement produces lower time-averaged pressures and pressure fluctuations on the water-rock interface and inside fissures, due to the shear between the downward current of the incoming jet and the upward current of the deflected wall jet. This is superposed with the effect of the entrained air bubbles, which reduce pressures due to the lower jet momentum but also increase pressures due to the reduction of the velocity decay in the pool. The influence of aerated jets impinging on a confined bottom is a superposition of the three effects and is strongly dependent on the relative pool depth.

A pool bottom confinement also changes the structure of the spectral content of the turbulent flow. Turbulent energy is concentrated at lower frequencies for the laterally confined bottom case, due to a more developed jet in the shear layer.

If the block embedded in the pool bottom is free to move vertically, the pressures inside the fissures are attenuated compared to a fixed block, due to the block's vibrations. This also has an important effect on the resonance phenomena inside the fissures, as 
it significantly reduces the celerity of the pressure waves propagating inside the rock joints. This behavior is similar to the description of the water-hammer celerity in closed-conduits, but with a pseudo-elasticity of the flow boundaries.

\section{Acknowledgements}

This research project was funded by the Portuguese Foundation for Science and Technology (FCT, Portugal, Grant No. SFPH/BD/ 51074/2010) and LCH-EPFL.

\section{References}

Beltaos, S., and Rajaratnam, N. 1977. Impingement of Axisymmetric Developing Jets. Journal of Hydraulic Research, 15: 311-326. doi:10.1080/00221687709499637. Bollaert, E. 2002. Transient water pressures in joints and formation of rock scour due to high-velocity jet impact. In Communication $\mathrm{N}^{\circ} 13$. Edited by Schleiss, A.J. Laboratory of Hydraulic Constructions (LCH), École Polytechnique Fédérale de Lausanne (EPFL), Switzerland.

Bollaert, E., and Schleiss, A.J. 2003a. Scour of rock due to the impact of plunging high velocity jets Part I: A state-of-the-art review. Journal of Hydraulic Research, 41: 451-464. doi:10.1080/00221680309499991.

Bollaert, E., and Schleiss, A.J. 2003b. Scour of rock due to the impact of plunging high velocity jets Part II: Experimental results of dynamic pressures at pool bottoms and in one- and two-dimensional closed end rock joints. Journal of Hydraulic Research, 41: 465-480. doi:10.1080/00221680309499992.

Bollaert, E., and Schleiss, A.J. 2005. Physically based model for evaluation of rock scour due to high-velocity jet impact. Journal of Hydraulic Engineering, 131: 153-165. doi:10.1061/(ASCE)0733-9429(2005)131:3(153).

Chassaing, P. 2000. Turbulence en mécanique des fluides: analyse du phénomène en vue de sa modélisation à l'usage de l'ingénieur. CépaduèsEditions.

Chaudhry, H. 2014. Applied Hydraulic Transients. Springer-Verlag New York, N.Y.

Duarte, R. 2013. Air concentrations in plunge pools due to aerated plunging high-velocity jets and dynamic pressures in underlying fissures, In Proceedings of 35th IAHR World Congress. TPI, Chengdu, China, pp. 1-10.

Duarte, R., Schleiss, A.J., and Pinheiro, A. 2013. Dynamic pressure distribution around a fixed confined block impacted by plunging and aerated water jets. In 35th IAHR World Congress. TUP, Chengdu, China, pp. 1-8.

Duarte, R., Schleiss, A.J., and Pinheiro, A. 2015. Influence of jet aeration on pressures around a block embedded in a plunge pool bottom. Environmental Fluid Mechanics, 15(3): 673-693. doi:10.1007/s10652-014-9392-x.

Federspiel, M.P.E.A. 2011. Response of an embedded block impacted by highvelocity jets. In Communication $\mathrm{N}^{\circ} 47$. Edited by Schleiss, A.J. Laboratory of Hydraulic Constructions (LCH), École Polytechnique Fédérale de Lausanne (EPFL), Switzerland

Ghidaoui, M.S., McInnis, D.A., Axworthy, D.H., and Zhao, M. 2005. A Review of Water Hammer Theory and Practice. Applied Mechanics Reviews, 58: 49-76. doi:10.1115/1.1828050.

Hachem, F.E., and Schleiss, A.J. 2011. A review of wave celerity in frictionless and axisymmetrical steel-lined pressure tunnels. Journal of Fluids and Structures, 27: 311-328. doi:10.1016/j.jfluidstructs.2010.11.009.

Halliwell, A.R. 1963. Velocity of a waterhammer wave in an elastic pipe. Journal of the Hydraulics Division, 89: 1-21.

Manso, P.F.A. 2006. The influence of pool geometry and induced flow patterns in rock scour by high-velocity plunging jets. In Communication $\mathrm{N}^{\circ} 25$. Edited by Schleiss, A.J. Laboratory of Hydraulic Constructions (LCH), École Polytechnique Fédérale de Lausanne (EPFL), Switzerland.

Manso, P., Bollaert, E., and Schleiss, A.J. 2007. Impact pressures of turbulent high-velocity jets plunging in pools with flat bottom. Experiments in Fluids, 42: 49-60. doi:10.1007/s00348-006-0219-5.

Manso, P.F.A., Bollaert, E.F.R., and Schleiss, A.J. 2008. Evaluation of high-velocity plunging jet-issuing characteristics as a basis for plunge pool analysis. Journal of Hydraulic Research, 46: 147-157. doi:10.1080/00221686.2008.9521852.

Manso, P.A., Bollaert, E.F.R., and Schleiss, A.J. 2009. Influence of plunge pool geometry on high-velocity jet impact pressures and pressure propagation inside fissured rock media. Journal of Hydraulic Engineering, 135: 783-792. doi:10.1061/(ASCE)HY.1943-7900.0000090.

Mason, P.J. 1989. Effects of air entrainment on plunge pool scour. Journal of Hydraulic Engineering, 115: 385-399. doi:10.1061/(ASCE)0733-9429(1989)115: 3(385).

Mason, P.J., and Arumugam, K. 1985. Free jet scour below dams and flip buckets. Journal of Hydraulic Engineering, 111: 220-235. doi:10.1061/(ASCE)07339429(1985)111:2(220).

Schleiss, A.J. 2002. Scour evaluation in space and time - the challenge of dam designers. In Rock Scour due to falling high-velocity jets. Edited by Schleiss, A.J., and Bollaert, E. Swets and Zeitlinger, Netherlands, pp. 3-22.

\section{List of symbols}

$C_{\mathrm{p}}$ time-averaged pressure coefficient (-)

$C_{p}^{\prime}$ pressure fluctuations coefficient (-)

$D$ pipe diameter $(\mathrm{m})$

E Young's modulus of elasticity (Pa)

$H$ difference between reservoir and tailwater levels (m)

$L_{\mathrm{f}}$ fissure length (m)

$K_{\text {aw }}$ bulk modulus of elasticity of the air-water mixture (Pa)

$P_{\mathrm{xx}}$ power spectral densities of the pressure fluctuations $\left(\mathrm{Pa}^{2} / \mathrm{Hz}\right)$

$Q_{\mathrm{a}}$ jet total entrained air discharge $\left(\mathrm{m}^{3} / \mathrm{s}\right)$

$Q_{\mathrm{aa}}$ jet air discharge at issuance $\left(\mathrm{m}^{3} / \mathrm{s}\right)$

$Q_{\mathrm{aw}}$ jet total discharge at issuance $\left(\mathrm{m}^{3} / \mathrm{s}\right)$

$Q_{w}$ jet water discharge $\left(\mathrm{m}^{3} / \mathrm{s}\right)$

$T_{\mathrm{u}}$ turbulence intensity (-)

$Y$ pool depth $(\mathrm{m})$

$V_{\text {aw }}$ jet velocity at issuance $(\mathrm{m} / \mathrm{s})$

$V_{\mathrm{i}}$ jet velocity at the plunge section $(\mathrm{m} / \mathrm{s})$

$Y$ ' distance between pressure transducer and pool surface $(\mathrm{m})$

$c$ celerity $(\mathrm{m} / \mathrm{s})$

$d_{\text {c }}$ confinement diameter $(\mathrm{m})$

$d_{\mathrm{j}}$ jet diameter at issuance $(\mathrm{m})$

$d_{\mathrm{m}}$ mean sediment or rock length $(\mathrm{m})$

$e_{\mathrm{c}}$ conduit wall thickness $(\mathrm{m})$

$f$ frequency $(\mathrm{Hz})$

$f_{\text {res }}$ resonance frequency (fundamental) $(\mathrm{Hz})$

$f_{\text {res1 }}$ resonance frequency for the entire fissure $(\mathrm{Hz})$

$f_{\text {res2 }}$ resonance frequency due to partial reflections in the horizontal fissure $(\mathrm{Hz})$

$g$ gravitational acceleration $\left(\mathrm{m} / \mathrm{s}^{2}\right)$

$h$ pool depth above initial riverbed $(\mathrm{m})$

$p$ pressure $(\mathrm{Pa})$

p' RMS of the pressure fluctuations $(\mathrm{Pa})$

$p_{\text {mean }}$ time-averaged pressure $(\mathrm{Pa})$

$q$ flow rate $\left(\mathrm{m}^{2} / \mathrm{s}\right)$

$y_{\mathrm{c}}$ core development length $(\mathrm{m})$

$t_{\mathrm{c}}$ scour depth $(\mathrm{m})$

$\alpha_{1}, \ldots \alpha_{5}$ exponential coefficients (-)

$\beta$ total jet aeration (or air-to-water ratio) (-)

$\beta_{1}$ jet aeration at issuance (-)

$\rho_{\mathrm{a}}$ density of air $\left(\mathrm{kg} / \mathrm{m}^{3}\right)$

$\rho_{\mathrm{aw}}$ density of the air-water mixture $\left(\mathrm{kg} / \mathrm{m}^{3}\right)$

$\rho_{\mathrm{w}}$ density of water $\left(\mathrm{kg} / \mathrm{m}^{3}\right)$ 